\title{
Dr. Adachi and Dr. Lau reply
}

To the Editor:

Osteonecrosis of the jaw associated with bisphosphonate use is an extremely rare but devastating complication. It is of interest to us that $\mathrm{Yu}$, et al have shared our experience with the use of teriparatide in those who do not respond to conservative treatment. This case report and others ${ }^{1,2}$ suggest that there might be a role for the use of teriparatide in those with osteonecrosis of the jaw associated with bisphosphonate use.

JONATHAN D. ADACHI, MD, FRCPC, St. Joseph's Hospital, 501-25 Charlton Avenue East, Hamilton, Ontario L8N 1Y2, Canada; ARTHUR LAU, MD, McMaster University, Internal Medicine, Hamilton, Ontario, Canada. Address correspondence to Dr. Adachi;

E-mail: jd.adachi@sympatico.ca

\section{REFERENCES}

1. Harper R, Fung E. Resolution of bisphosphonate-associated osteonecrosis of the mandible: possible application for intermittent low-dose parathyroid hormone [rhPTH(1-34)]. J Oral Maxillofac Surg 2007;65:573-80.

2. Lau AN, Adachi JD. Resolution of osteonecrosis of the jaw after teriparatide [recombinant human PTH-(1-34)] therapy. J Rheumatol 2009;36:1835-7.

J Rheumatol 2010;37:3; doi:10.3899/jrheum.091085 